\title{
DISCUTINDO GÊNERO E DIVERSIDADE ÉTNICO RACIAL: A INCLUSÃO A PARTIR DO DESIGN INCLUSIVO NOS LIVROS MULTISSENSORIAIS
}

Alessandra Lopes de Oliveira Castelini Denise Regina Quaresma da Silva ${ }^{2}$ Regina de Oliveira Heidrich ${ }^{3}$

Resumo: Este artigo tem como objetivo ampliar a visibilidade da necessária discussão sobre diversidade étnico-racial e inclusão a partir do design inclusivo em livros multiformato, que se apresentam enquanto artefatos culturais, no debate educacional e interdisciplinar. Metodologicamente, trata-se de um estudo de natureza bibliográfica, de caráter qualitativo e embasa-se nos estudos propostos por Bauman (2001, 2005,2009); Castel e Quaresma da Silva (2017); Martins (2002; 2009); Cavaleiro (1999); Dias (1997); Fischer (2001); Hall (1997); Rosenberg (1996) e Scott (1995). Concluímos que o estudo sobre a diversidade étnico-racial nos livros multissensoriais de design inclusivo é um importante auxiliar no papel fundamental da formação inicial e continuada de docentes, para aqueles que vão atuar na primeira etapa da educação básica, bem como nas demais modalidades de ensino e outros contextos escolares ou não escolares, como forma de desenvolver e contribuir com a construção da afirmação da identidade de gênero e racial desde a educação infantil. o estudo de temas sociais, da diversidade e inclusão nos permitem a desmistificação do tema e contribuem na edificação de críticas

\footnotetext{
${ }^{1}$ Doutoranda em Diversidade Cultural e Inclusão Social - PPGDI - Feevale/RS. Mestre em Educação (UNICENTRO/PR). Docente da Universidade Federal do Piauí (UFPI/CSHNB). E-mail: alessandralopes@ufpi.edu.br

${ }^{2}$ Bolsista de Produtividade em Pesquisa do CNPq - Nível 2 - CA ED - Educação. Pós-Doutora em Estudos de Gênero pela UCES (2011), Doutora (2007) e Mestre (2003) pela Universidade Federal do Rio Grande do Sul, Psicóloga. É professora Titular e pesquisadora da Universidade FEEVALE no Programa de PósGraduação em Diversidade Cultural e Inclusão Social e do PPG em Educação da Universidade La SalleCanoas/RS.. http://buscatextual.cnpq.br/buscatextual/visualizacv.do?id=K4772827H9.

E-mail: denisequaresmadasilva@gmail.com . http://orcid.org/0000-0002-3697-8284

Educação da Universidade La Salle-Canoas/RS. E-mail: denisequaresmadasilva@gmail.com

${ }^{3}$ Pesquisadora do CNPq. Pós Doutora pela Universidade Técnica de Lisboa (UTL), Doutora em Informática na Educação. Docente do Programa de Pós-Graduação em Diversidade Cultural e Inclusão Social da Universidade Feevale/RS. E-mail: rheidrich@feevale.br
} 
http://periodicos.ufpb.br/ojs2/index.php/ged/index

construtivas e identificação da responsabilidade do Estado nos processos de exclusão e inclusão social na perspectiva dos Direitos Humanos, sobretudo àqueles que são as maiores vítimas do sistema econômico, tornando necessário o comprometimento rigoroso da elaboração cientifica, da crítica social, tornando-se necessário o deslocamento dos pontos de vista, do nosso olhar, considerando a compreensão do contexto histórico e social desses fenômenos bem como suas contradições e complexidades.

Palavras-chave: Diversidade; Inclusão; Livros Multissensoriais; Estudos ÉtnicoRaciais; Formação de Docentes; Direitos Humanos.

Abstract: This article aims to broaden the visibility of the necessary discussion on ethnic-racial diversity and inclusion from the inclusive design in multiformat books, which present themselves as cultural artifacts in the educational and interdisciplinary

debate.

Methodologically, it is a study of a bibliographic nature, of a qualitative nature and based on the studies proposed by Bauman (2001, 2005,2009); Castel and Quaresma da Silva (2017); Martins (2002; 2009); Knight (1999); Dias (1997); Fischer (2001); Hall (1997); Rosenberg (1996) and Scott (1995). We conclude that the study of ethnic-racial diversity in multisensorial books of inclusive design is an important auxiliary to the fundamental role of initial and continuing teacher training for those who will be involved in the first stage of basic education, as well as in other teaching modalities and other school or nonschool contexts, as a way to develop and contribute to the construction of the affirmation of gender and racial identity from kindergarten. the study of social issues, diversity and inclusion allow us to demystify the theme and contribute to the construction of constructive criticism and identification of the State's responsibility in the processes of exclusion and social inclusion in the perspective of Human Rights, especially to those who are the economic system, making necessary the rigorous commitment of the scientific elaboration, of the social critique, making necessary the displacement of the points of view, of our gaze, considering the understanding of the historical and social context of these 
phenomena as well as their Bauman (2001, 2005,2009); Castel e contradictions and complexities.article discusses issues related to gender violence and presents the intervention proposal of an extension.

Quaresma da Silva (2017); Martins (2002; 2009); Cavaleiro (1999); Dias (1997); Fischer (2001); Hall (1997); Rosenberg (1996); Scott (1995), Soler (1999); dentre outros.

KeyWords: Diversity; Inclusion; Ancorando-se na revisão de Multisensory Books; Ethnic-Racial Studies; Teacher Training; Human rights.

\section{Introdução}

Este trabalho tem como objetivo ampliar a visibilidade da necessária discussão sobre diversidade étnico-racial e inclusão a partir do design inclusivo ${ }^{4}$ em livros multiformato, que se apresentam enquanto artefatos culturais, no debate educacional e interdisciplinar.

Metodologicamente, este estudo é de natureza bibliográfica, de caráter qualitativo (MARTINS, 2004b) e embasa-se nos estudos propostos por

\footnotetext{
4 Trata-se de uma abordagem geral para a concepção de projetos em que os designers garantem que seus produtos e serviços atendam ás necessidades do maior público possível, independentemente da idade ou habilidade. (KEATS, CLARKSON et al., 2002, p. 235)

${ }^{5}$ Conforme FÉLIX (2015), com a criação da Secretaria de Educação Continuada, Alfabetização e Diversidade (SECAD/MEC), em 2004, novamente temas como gênero, sexualidade e diversidade ganharam força no âmbito das políticas públicas educacionais de gestão nacional. Isso se refletiu em processos
}

formativos e publicações voltados a qualificar professores/as para abordar questões articuladas aos que ali eram chamados de temas da diversidade.

${ }^{6}$ A educação inclusiva constitui um paradigma educacional fundamentado na concepção de direitos humanos, que conjuga igualdade $\mathrm{e}$ diferença como valores indissociáveis, e que avança em relação à ideia de equidade formal ao contextualizar as circunstâncias históricas da produção da exclusão dentro e fora da escola. (BRASIL, 2008, p. 1). 
exclusão social, tornando possível ampliar os argumentos acerca dos conceitos de desigualdade, das consequências da globalização e dos novos modos de inserção e exclusão social bem como suas contradições, articulando essas analises com questões relativas à educação, ao trabalho, à saúde, entre outras interfaces e a identificação da responsabilidade do Estado nos processos de inclusão e exclusão social e o nosso trabalho enquanto militantes no contexto da construção da crítica científica.

\section{A Educação no Contexto Líquido da}

\section{Atualidade}

Ao analisar as profundas e radicais transformações ocorridas no campo da educação, indissociáveis da nova conjuntura política e econômica no Brasil desde o ano de 2016, marcadas pelo golpe político - ou de forma mais confortável, "impeachment" da presidente eleita Dilma Rousseff - e da instauração do novo governo que incorpora no bloco do poder a coalização de forças políticas derrotadas no processo eleitoral de 2014, nos revelam à luz das leituras empreendidas, a compreensão histórica dessa sociedade "líquido-moderna", conceito este utilizado por Bauman (2001, p.07) ao afirmar que "é a sociedade em que as condições sob as quais agem seus membros mudam num tempo mais curto do que aquele necessário para a consolidação, em hábitos e rotinas, das formas de agir", possibilitando a discussão sobre essa "vida líquida" como uma vida precária, vivida em condições de incertezas constantes.

Por acreditarmos que as discussões aqui empreendidas se fazem pertinentes no meio acadêmico/social e no debate educacional da atualidade, não podemos deixar de considerar o momento histórico que estamos emergidos no Brasil, sufocado numa crise multidimensional que agrava as violações de direitos humanos e acelera a perda de direitos conquistados pelos movimentos sociais na história, implicando na fragilização da jovem democracia brasileira, da mobilização social, nas novas formas de exclusão e da pobreza, na clandestinidade do trabalho, nas migrações, etc., provocando a desmobilização da crítica ao sistema e na inclusão degradada. 
Concordamos com Castel (2000, p.12) ao tratar que "a questão social configura-se como uma dificuldade central, da qual essa sociedade se interroga sobre sua coesão e suas fraturas", expondo em sua obra "Desigualdade e a Questão Social" as armadilhas da exclusão, os perigos da vulnerabilidade do trabalho, sua precarização e submissão à ordem do mercado, o qual "vem gerando trabalhadores excedentes, sobrantes inválidos.”

Nessa perspectiva, analisando a atual conjuntura brasileira e a importância da pesquisa com caráter social (MINAYO, 1994), este estudo apresenta-se também como uma forma de denúncia às violações históricas e da atualidade, seja contra os povos tradicionais, a população negra e pobre das periferias urbanas brasileiras, as minorias, os despossuídos, os sobrantes, inválidos, excluídos, entre outros, os quais marcaram e continuam marcando profundamente a sociedade.

Nos estudos realizados para este artigo, foi possível perceber por meio da obra de José de Souza Martins, intitulada "A Sociedade vista do Abismo - Novos estudos sobre Exclusão, Pobreza e
Classes Sociais" lançado em 2002 e a obra "Exclusão Social e a nova desigualdade" lançado em 2009, que o autor também recorre a uma denúncia ao relatar que parte dos problemas sociais, podem ser decorrentes de crises econômicas ou de políticas econômicas (governantes, políticos e economistas) que podem "criar as crises" (MARTINS, 2009, p.12).

Para Martins (2002), o conceito de exclusão social que almeja classificar as desigualdades sociais contemporâneas é duramente criticado, visto que a categoria "excluído" não é verificável na prática, na vida cotidiana, porque o pobre hoje aderiu às características fundantes da sociedade capitalista contemporânea, e estão como toda a população mergulhados na sociedade do consumo.

Ao analisar alguns aspectos da vida cotidiana, das camadas mais pobres da sociedade, ou dos chamados “excluídos”, Martins (2002) denomina enquanto aspectos da inclusão degradada, como por exemplo a violência e o preconceito.

A degradação moral faz parte da maioria da população brasileira, que está incluída, mas à margem do sistema capitalista, visto que sobrevive dos restos 
que ela mesma produz para as elites do país. O mais interessante nesta análise, é a constatação que essa população não sente-se excluída, pois de fato ela não está, pois essa população trabalha, mesmo que em condições precárias, produz e consome, ou seja, faz parte da sociedade.

Dessa forma, uma reivindicação de Martins (2002) é que os intelectuais e militantes brasileiros devem priorizar na pauta das discussões é a chamada "equidade social", problematizando as fronteiras dessa sociedade que nos separam e que permitem a cidadania, ou seja, o acesso à educação de qualidade, à cultura, à condições econômicas e políticas dignas somente a uma parte da população brasileira.

Além de discutir sobre o campesinato, às migrações e o problema da questão agrária do Brasil, Martins(2002) trata da escravidão moderna em nossa sociedade a qual é "viabilizada e revigorada pelo poder da tradição e pela função que ela exerce no processo de desenvolvimento do capitalismo entre nós". A esse fenômeno, Martins (2002, p.159) intitula de uma "irracionalidade social" que cumpre uma função histórica na racionalidade econômica, visto que a escravização ocorre sobretudo em estabelecimentos econômicos com características de enclaves territoriais, incluindo questões de confinamento, privação de liberdade e dos seus direitos sociais.

Martins (2009) ao discutir sobre a nova desigualdade postula que as reações ocorrem dentro da realidade que a produziu, ou seja, frequentemente são balizados a partir dos interesses do mercado financeiro, dos grandes empresários e políticos - nesse caso especifico tratando dos brasileiros envolvidos em denúncias de corrupção, superfaturamento e mal uso da máquina pública, (LEHER, VITTORIA, e MOTTA, 2017) impedindo a governabilidade da presidente reeleita em 2014, atrelados às articulação de setores dominantes tradicionais, representados pelos partidos da "ordem", representando os interesses da "nova direita" (as bancadas da bíblia com 197 deputados e da bala, das empreiteiras e do boi com orientação de direita com mais de 250 deputados de um total de 
$513)^{7}$, exigindo aprovação de projetos que significam um recuo na laicidade do Estado, - como por exemplo o Projeto Escola Sem Partido - regressão na secularização, operando por meio do moralismo, o medo de qualquer mudança social, resultando em mudanças vertiginosas no País. (LEHER, VITTORIA, e MOTTA, 2017)

Essas mudanças que estão ocorrendo de forma aceleradas estão desencadeando profundos retrocessos na sociedade brasileira, impedindo a realização da reforma política efetiva, da ampliação dos programas sociais e do necessário empoderamento popular, facultando a base comunitária e social suscetível do Brasil ao apagamento/silenciamento por instituições antipopulares e ultraconservadoras.

A partir de 1990 com a implantação do neoliberalismo no Brasil, observamos que houve a implicação proposital da inclusão precária, instável e marginal, o que para Martins (2009, p.20) foi um meio que atenuou a confletividade social de classe, politicamente perigosa para as classes dominantes, visto que a retorica populista da exclusão, lança a cilada de discutir o que não está acontecendo, impedindo de discutir o que de fato acontece, ou seja, podemos até discutir a exclusão, mas infelizmente deixamos de discutir as formas pobres e indecentes da inclusão.

Com isso, percebemos que as novas categorias sociais geradas pela exclusão, conforme Martins (2009) degradam o ser humano, pois retiram-lhe o que é próprio - o gênero humano, o homem livre, num reino de justiça e igualdade.

Nesse contexto, podemos refletir também de forma mais especifica sobre os desafios educacionais na modernidade líquida, dialogando com Bauman (2009) e seus escritos sobre a Educação, ao concordar que hoje a educação é eternamente inconclusa, pois a sociedade do consumo está em constante mudança. Dessa forma, o conhecimento tornou-se flexível e vem cercado o imediatismo, único, pronto para o uso, disponível, imediato, acelerado. Flexibilidade tornou-se a palavra do momento.

\footnotetext{
${ }^{7}$ Dados de 2015 que constam da pesquisa de LEHER, VITTORIA, e MOTTA (2017)
} 
Um exemplo dessas

modificações no campo educacional é a presença de alunos com necessidades educacionais especiais na rede regular de ensino. A educação inclusiva evoluiu como conceito, reflexo de inúmeras discussões que ocorreram desde os anos 90, dentre as quais podemos destacar a Declaração de Salamanca (UNESCO,1994), documento que originou da Conferência Mundial da Educação Especial que ocorreu na Espanha no ano de 1994.

Com o objetivo de encontrar metodologias que atendam as diferentes necessidades dos alunos, a perspectiva da didática multissensorial (SOLER,1999) a qual possibilita benefícios tanto quantitativos pois há um aumento de pessoas com possibilidades reais de perceber informações cientificas, quanto qualitativos que consiste no aumento da quantidade de informações recebidas, contribuindo assim para a formação de conceitos com significados mais completos. Daí parte o nosso interesse pela perspectiva da diversidade por meio dos livros multissensoriais.

Portanto, afirmamos que faz-se necessário a flexibilização do conhecimento, atualmente todo conhecimento é transformado em informação, o qual pode apresentar-se ultrapassado rapidamente, tornando-se enganoso, gerando desconfiança. (BAUMAN,2001)

A partir desse enfoque, discutir a formação profissional docente (COELHO,2012) tenciona os princípios da tarefa educativa, desestabiliza uma vez que os cursos exigem formação à curto prazo, cursos flexíveis, estudos autodidatas, conteúdos atraentes e a necessidade de constante atualização.

\section{Inclusnao e Diversidade a partir dos} livros Multisensoriais

Considerando as demandas da nossa sociedade, em constantes transformações (BAUMAN, 2001) e atravessada pela reivindicação de projetos ultraconservadores e que representam um retrocesso à humanidade, apresentamos nesse trabalho a importância de fomentar às discussões acerca dos estudos à respeito da Diversidade Cultural e Inclusão Social com ênfase na formação de docentes. 
Das temáticas da atualidade, propostos pelo Programa de PósGraduação da Feevale ${ }^{8} / \mathrm{RS}$, manifestamos o interesse de ampliar as discussões, repercutindo sobre temas da diversidade étnico-racial na perspectiva do design inclusivo e da criação e difusão de artefatos culturais enquanto potencialidades para a discussão dos estudos da Educação para as Relações Étnico-Raciais ${ }^{9}$, conduzindo implicações para a atuação profissional docente interdisciplinar, o qual repercute diretamente nos espaços educativos escolares e não escolares, em diferentes etapas, analisando se os recursos literários apresentados ao leitor - no contexto das multideficiências ${ }^{10}$ valorizam ou não a diversidade com ênfase nas relações étnico-raciais, considerando que os livros

\footnotetext{
8 Disponível em https://www.feevale.br/posgraduacao/stricto-sensu/programa-de-posgraduacao-em-diversidade-cultural-e-inclusaosocial Acesso em Nov. 2018

${ }^{9}$ Entendemos a Educação das Relações ÉtnicoRaciais conforme expresso no CNE/CP 003/2004 o qual dispõe sobre as aprendizagens construídas entre brancos e negros, pautadas nas trocas de conhecimentos, quebra de desconfianças, projeto conjunto para construção de uma sociedade justa, igual, equânime. Essa reeducação não é tarefa exclusivamente da escola e precisa ser pensada enquanto projeto de sociedade.

${ }^{10}$ Para autores como Orelove e Sobsey (2000), a multideficiência é caraterizada por uma combinação de limitações acentuadas no
}

multissensoriais como contributo pedagógico, manifestam características potencializadoras para o fomento das discussões acerca da diversidade e da inclusão social ${ }^{11}$.

Os livros multissensoriais ${ }^{12}$ ou multiformato enquanto artefatos culturais de design inclusivo fazem parte do projeto intitulado "SENSeBOOKS livros multissensoriais" - a partir do convênio estabelecido com a CAPES e a Universidade Feevale/RS e o Instituto Politécnico de Leiria - IPL - em Portugal.

A relevância do tema pressupõe que as instituições educativas ao propor a criação e difusão de materiais inclusivos literários, constituem-se como espaços privilegiados de socialização e saberes, os quais são representados no modo como os sujeitos nas suas relações

domínio cognitivo, motor e/ou sensorial. Saramago et al. (2004) referem também que este tipo de população apresenta graves problemas em mais de um domínio, sendo um deles relacionado com as limitações cognitivas.

${ }^{11}$ Utilizamos o conceito de inclusão social como um tema que tem sido amplamente discutido na atualidade e como refere Bartalotti (2006), é entendido como um direito.

12 Segundo SOLER (1999. p.45) é um método pedagógico de interesse para o ensino e aprendizagem que utiliza todos os sentidos humanos possíveis para captar informações do meio que nos rodeia e inter-relaciona estes dados a fim de formar conhecimentos multissensoriais completos e significativos. 
sociais recebem ou não a interferência de diferentes símbolos, discursos e práticas que corroboram para a reconstrução dos seus papéis sociais bem como suas disposições, aspectos culturais $^{13} \mathrm{e}$ formas de ser e estar no mundo.

Concordamos com Heidrich (2004) ao afirmar que a inclusão é um processo social que extrapola em muito os aspectos escolares e que deve ser realizado um esforço constante para permitir que pessoas com deficiência tenham espaços reais de inclusão que as permitam continuar se desenvolvendo fora do âmbito escolar e nos dias atuais as Tecnologias da Informação e Comunicação - TIC's as quais possibilitam diminuir os problemas de acessibilidade e ajudá-los com a dificuldade de comunicação.

Sob essa questão a Lei Brasileira de Inclusão da Pessoa com Deficiência (BRASIL, 2015) expressa bem a ideia discutida acima, sobretudo no Artigo 102 o qual afirma que "os produtos, ambientes, programas e serviços a serem usados por todas as pessoas, sem necessidade de adaptação ou de projeto

\footnotetext{
${ }^{13}$ Conceituamos a cultura na perspectiva de Hall (1997) como um dos elementos mais dinâmicos e mais imprevisíveis da mudança histórica do novo milênio;
}

específico, incluindo os recursos de tecnologia assistiva". (BRASIL, 2015, p.29)

Por isso, ao contemplar uma Educação para $\operatorname{Todos}^{14}$, não podemos esquecer que o trabalho com identidade, diferença e diversidade torna-se imprescindível para a construção de metodologias, materiais e processos de comunicação possibilitando atender $\mathrm{o}$ que é comum e o que é específico aos estudantes. (CAMARGO, 2017)

$\mathrm{O}$ interesse em analisar os livros multissensoriais produzidos a partir desse projeto respaldam-se nos desafios e possibilidades que permeiam a Educação Inclusiva ERER - conforme obrigatoriedade na educação básica prevista na Lei $n^{\circ} \quad 10.639 / 2003$ (BRASIL, 2003), que trata da obrigatoriedade do ensino de história e cultura Africana e Afro-Brasileira na Educação Básica e das orientações expressas no Parecer CNE/CP 03/2004 (BRASIL,2004), busca-se delimitar o viés do universo acadêmico como espaço de formação e produção de conhecimento e da diversidade, e, neste

14 Em referência a Conferência Mundial de Educação para Todos - realizada em Jontien/Tailândia em 1990. 
caso, das universidades conveniadas, os quais promovem a formação de profissionais para atuar em diferentes modalidades da educação e que desempenham um papel de articuladores e multiplicadores na gestão da ERER nos espaços educativos, envolvidos numa multiplicidade de contextos, conforme evidencias já apresentadas nos estudos anteriores.(CASTELINI, 2016)

Ao investigar as questões relativas à literatura infantil como parte do universo formativo da criança, compreendemos que as obras literárias se constituem artefatos culturais, os quais para Strobel (2008, p.35) "consiste em produções culturais do sujeito que tem seu próprio modo de ser, ver, entender e transformar o mundo", os quais estão presentes em diversos contextos educativos e sociais, sejam escolares ou não escolares. A linguagem literária por se constituir um campo discursivo, estrutura-se em mecanismos que nos permitem visualizar e analisar quais são os modelos de infância ou representações que são apresentados pelos textos narrativos.

$\mathrm{O}$ estudo "Discutindo as Relações de Gênero e Étnico-Raciais por meio dos Contos de Fadas na Educação
Infantil" (CASTELINI E QUARESMA

DA SILVA, 2018), colabora para essa possível compreensão, explorando o caráter pedagógico e moralizante existentes nos textos literários infantis, os quais muitos sugerem em seus discursos padrões comportamentais, impondo regras sociais e morais as quais são amplamente valorizadas pela sociedade enquanto práticas culturais.

Nas palavras de Hall (1997), ao conceituar o significado de prática cultural, nos leva a compreensão que:

Cada instituição ou atividade social gera e requer seu próprio universo distinto de significados e práticas - sua própria cultura. Assim sendo, cada vez mais, o termo está sendo aplicado às práticas e instituições, que manifestamente não são parte da - esfera cultural, no sentido tradicional da palavra. De acordo com este enfoque, todas as práticas sociais, na medida em que sejam relevantes para o significado ou requeiram significado para funcionarem, têm uma dimensão - cultural. (HALL, 1997, p.13)

Nesse sentido, compreendemos a prática pedagógica como uma prática cultural, considerando-a como parte da cultura. Nos estudos de Moreira e Candau (2003, p.160), os autores enfatizam que "as relações entre escola e 
cultura não podem ser concebidas como entre dois polos independentes, mas sim como universos entrelaçados, como uma teia tecida no cotidiano e com fios e nós profundamente articulados".

Por conseguinte, consideramos a literatura infantil inserida no campo dos estudos culturais, por entender a cultura como campo de luta em torno da significação social (SILVA, 1999, p.133-134), podendo ressignificá-la enquanto artefato cultural que além de cumprir com seu papel formativo de construção de sentidos e valores socialmente construídos (morais, sociais, educativos, éticos e estéticos) apresentase como uma produção discursiva de saberes e fazeres sobre as infâncias e as crianças.

A pedagogização da literatura infantil, historicamente pode ser datada desde o século XVIII, a qual constitui-se um espaço subsidiário profícuo para conformação dos objetivos da pedagogia de governar a infância, pois considerando a linguagem literária "como campo discursivo afetado pelo

\footnotetext{
${ }^{15}$ Entendemos a Educação das Relações ÉtnicoRaciais conforme expresso no $\mathrm{CNE} / \mathrm{CP}$ 003/2004 o qual dispõe sobre as aprendizagens construídas entre brancos e negros, pautadas nas trocas de conhecimentos, quebra de
}

contexto histórico-social, torna-se possível analisar quais representações de criança foram se imprimindo, conscientemente, ou não, ao longo da história das narrativas infantis" (ALCÂNTARA, 2010, p.19)

Com esse repertório de textos e imagens - seja pela qualidade dos livros dispostos no seu material gráfico, nas imagens e até mesmo nos sons e recursos que tornam possível uma maior interação com os leitores, acaba seduzindo $\mathrm{o}$ imaginário tanto adulto quanto infantil, principalmente para o público da etapa da Educação Infantil e Anos Iniciais do Ensino Fundamental.

No Brasil, desde 2003 com a publicação da Lei Federal $\mathrm{n}^{\circ}$ 10.639/2003 e pela Lei 11.645/2008 que inclui e torna obrigatório o ensino de história e cultura afro-brasileira, africana e indígena em todos os sistemas de ensino, e em 2004 com a aprovação das Diretrizes Curriculares Nacionais para a Educação das Relações Étnico-Raciais ${ }^{15}$ - DCNERER (BRASIL, 2004) o qual possibilitou mudanças significativas na

desconfianças, projeto conjunto para construção de uma sociedade justa, igual, equânime. Essa reeducação não é tarefa exclusivamente da escola e precisa ser pensada enquanto projeto de sociedade. 
organização curricular para o trabalho pedagógico com a temática étnico-racial.

$\mathrm{Na}$ literatura infantil, acompanhamos um impacto direto na produção editorial de obras destinadas ao público infantil nas quais destacam-se o discurso da valorização da diversidade cultural, afirmando positivamente a identidade afro-brasileira e a ancestralidade indígena e africana e suas culturas.

Dessa forma, faz-se necessário evidenciar que todos os educadores têm a tarefa, apoiados pelos gestores, seja da escola ou dos sistemas de ensino superior, de implementar nos respectivos espaços de atuação a Resolução do CNE/CP 1/2004 (BRASIL, 2004) e das Diretrizes Curriculares Nacionais para a graduação em nível superior DCNs/2015 (BRASIL, 2015) que referese a conteúdos específicos de conhecimentos interdisciplinares, como: direitos humanos, diversidades étnicoracial, de gênero, Língua Brasileira de Sinais - LIBRAS, entre outros, fornecendo elementos básicos, conhecimentos e habilidades necessários à docência permitindo maior respeito à diversidade humana, o que nas palavras de Bauman (2009, p.164) seria esse o duplo desafio da Educação na modernidade líquida: promover a socialização e a individualização nos mecanismos educacionais, ou seja, "tornar esse mundo mais hospitaleiro para a humanidade".

\section{Tecendo Algumas Perspectivas a Guisa de Conclusão}

Com o intuito de discutir algumas categorias emergentes nos estudos teóricos, é pertinente destacar a reflexão necessária sobre a naturalização do fenômeno exclusão/inclusão, bem como sobre os discursos acerca da desigualdade social e da modernidade liquida, tornando possível desconstruir alguns discursos dominantes no senso comum e perceber as ações contraditórias que permeiam essa discussão.

Por meio dos estudos e das discussões empreendidas tornou-se possível analisar que a perspectiva da exclusão envolve tanto a perspectiva do incluído quanto a do excluído, e que ao mesmo tempo elas são contraditórias.

Nesse sentido, ao identificar alguns pontos de convergência e divergência entre as leituras propostas, 
tornou-se possível ampliar a compreensão sobre a questão social na contemporaneidade. Tanto do ponto de vista sociológico, quanto do ponto de vista histórico, há uma preocupação na terminologia da "exclusão" o que proporciona a compreensão mais alargada do processo investigativo e a importância histórica dessa análise.

Neste sentido, a exclusão enquanto fenômeno social não caracteriza-se como um evento acidental, mas sobretudo é fruto de um produto histórico, do resultado de processos sociais e políticos que foram experimentados ao longo do tempo pela sociedade.

Outro aspecto relevante é a chamada dos autores para os "mediadores sociais e políticos pertencentes ao campo do ativismo social" que segundo Martins (2002) apresentam a temática da exclusão social em suas pautas políticas e a importância da intervenção junto às populações vulneráveis, aqui podemos incluir a atuação eficiente dos profissionais da educação.

Nessa assertiva, o estudo sobre a diversidade étnico-racial nos livros multissensoriais de design inclusivo nos leva a refletir sobre a necessária discussão sobre diversidade na contemporaneidade e o papel fundamental da formação inicial e continuada de docentes, para aqueles que vão atuar na primeira etapa da educação básica, bem como nas demais modalidades de ensino e outros contextos escolares ou não escolares, como forma de desenvolver e contribuir com a construção da afirmação da identidade de gênero e racial desde a educação infantil.

Reiteramos que a importância desse estudo, está ancorada na perspectiva que considera o quanto a ausência de discussões sobre a temática da diversidade no contexto educativo, sejam públicas ou privadas, prejudicam a formação humana, pois desencadeiam problemas crescentes de desigualdades, exclusão, violência moral, física, social e tantas outras, já que não é incentivado o desenvolvimento por uma cultura de aceitação de si, como parte de um grupo de valor, sem rotulações de quem seja inferior ou superior, melhor ou pior, mas, propor o fazer-se educar numa perspectiva de construção do indivíduo como um ser igual, independente de etnias, raças, crenças, valores, etc. 
Assim, compreendemos que o trabalho sistemático e contextualizado com a literatura a partir dos livros multissensoriais de design inclusivo, que buscam contemplar as multideficiências, podem contribuir para a expansão da cultura por meio da literatura africana e afro-brasileira permitindo às crianças negras ou brancas enxergar beleza no seu pertencimento racial, na sua pele e nos seus cabelos, contribuindo assim com a formação afirmativa da identidade das mesmas.

Sob esse ponto de vista, o aprofundamento das possibilidades da inclusão de temas da diversidade nos livros multissensoriais propõem uma reflexão ao partir do pressuposto que as narrativas, os personagens e até as próprias ilustrações apresentadas nos livros de histórias de literatura apresentadas, manifestam discursos e simbolismos que influenciam e repercutem em exclusões sociais, muitas das vezes, produzindo ou reproduzindo por meio de formas simbólicas que revelam e simbolizam hierarquias seja nas relações de gênero e étnico racial, pois colocam brancos/as de um lado, negros/as e indígenas de outro, ainda em que não operam para a emancipação ou para o respeito à diferença e a inclusão social.

Portanto, o estudo de temas sociais, da diversidade e inclusão nos permitem a desmistificação do tema e contribuem na edificação de críticas construtivas e identificação da responsabilidade do Estado nos processos de exclusão e inclusão social na perspectiva dos Direitos Humanos, sobretudo àqueles que são as maiores vítimas do sistema econômico, tornando necessário o comprometimento rigoroso da elaboração cientifica, da crítica social, tornando-se necessário o deslocamento dos pontos de vista, do nosso olhar, considerando a compreensão do contexto histórico e social desses fenômenos bem como suas contradições e complexidades.

\section{Referências}

ALCÂNTARA, Flávia. Representações de infância e literatura para crianças: duas faces de uma mesma moeda. In: COENGA, Rosemar (org.). A leitura em cena: literatura infanto-juvenil, autores e livros. Cuiabá: Carlini \& Caniato, 2010. 
BAUMAN, Zygmunt. Identidade. Rio de Janeiro: Zahar, 2005

Modernidade líquida. Rio

de Janeiro, 2001.

Vidas desperdiçadas. Rio

de Janeiro: Jorge Zahar, 2005

\section{Entrevista sobre a}

Educação: Desafios pedagógicos e

Modernidade Líquida - Alba

Porcheddu. Cadernos de Pesquisa, v.39, n.137, p.661-684, maio/ago. 2009.

Disponível

em:<http://www.scielo.br/pdf/cp/v39n1

37/v39n137a16 Acesso em Nov/2018.

BRASIL. Lei 9.394, de 20 de dezembro de 1996. Lei de Diretrizes e Bases da Educação Nacional. Brasília, DF: Ministério da Educação, 1996.

. Lei 10.639 de 9 de janeiro de 2003. Altera a Lei no 9.394, de 20 de dezembro de 1996, que estabelece as diretrizes e bases da educação nacional. Brasília: [s.n.], 2003.

\section{Diretrizes Curriculares}

Nacionais para a Educação das
Relações Étnico-Raciais e para o Ensino de História e Cultura AfroBrasileira e Africana. Brasília: [s.n.], 2004.

Conselho Nacional de Educação. Conselho Pleno. Parecer CNE/CP 3/2004 Diretrizes Curriculares para a Educação das Relações ÉtnicoRaciais e para o Ensino de História e Cultura afro-brasileira e Africana. Brasília, Ministério da Educação, 2004.

Lei 11.645, de 10/03/2008. Inclui no currículo oficial da rede de ensino a obrigatoriedade da temática "História e Cultura Afro-Brasileira e Indígena”. Disponível em: . Acesso em: Nov.2018

Política nacional de educação especial na perspectiva da educação inclusiva. Brasília, 2008. Disponível em: . Acesso em: Nov. 2018

Plano Nacional de implementação das Diretrizes Curriculares Nacionais para a Educação das Relações Étnico-Raciais e para o Ensino de História e Cultura 
Afro-Brasileira e Africana. Brasília: [s.n.], 2009.

. Conselho Nacional de Educação.

Define as Diretrizes Curriculares

Nacionais para a formação inicial em nível superior (cursos de licenciatura, cursos de formação pedagógica para graduados e cursos de segunda licenciatura) e para a formação continuada. Resolução CNE/CP n. 02/2015, de $1^{\circ}$ de julho de 2015 .

Lei no 13.146, de 6 de julho de

2015. Institui a lei brasileira de inclusão da pessoa com deficiência (estatuto da pessoa com deficiência). Brasília, 2015. Disponível em: . Acesso em: Nov. 2018.

CASTEL, R. A. As armadilhas da exclusão In:

BELFIOREWANDERLEY, $\mathrm{M}$; BÓGUS, L;YAZBEK, M. C. (Orgs.). Desigualdade e a questão social. São Paulo: EDUC, 2000.

CASTELINI, Alessandra Lopes de Oliveira. A Formação de Docentes para a Educação das Relações ÉtnicoRaciais no Município de Pitanga/PR: percursos da Lei 10.639/03. 2016. 226

p. Dissertação (Mestrado em Educação)

- Universidade Estadual do Centro-

Oeste, Guarapuava/PR, 2016.

Alessandra L. O;

QUARESMA DA SILVA, D. R. Discutindo as Relações de Gênero e Étnico-Raciais por meio dos contos de fadas na Educação Infantil. Cuadernos de Educación y Desarrollo, v.1, p.1-16 2018. Disponível em: http://https://www.eumed.net/rev/atlante 2018/05/educacao-infantil-brasil.html

CAVALLEIRO, Eliane. Do silêncio do lar ao silêncio escolar: racismo, preconceito e discriminação na educação infantil. 1998. Dissertação (Mestrado em Educação). Faculdade de Educação, Universidade de São Paulo, São Paulo.

CAMARGO, Eder Pires de. Inclusão Social, educação inclusiva e educação especial: enlaces e desenlaces. Revista Ciências Educação, Bauru, v.23, n.1, p.1-6, 2017. Disponível em: http://www.scielo.br/pdf/ciedu/v23n1/1 516-7313-ciedu-23-01-0001.pdf Acesso em Nov. 2018 
COELHO, W. de N. B. et al. Caminhos da Formação Docente no Brasil: desafios e perspectivas na contemporaneidade. Revista Reflexão e Ação. Santa Cruz do sul, v. 20, n. 1, p. 09-23, jan/junho. 2012

DIAS, Lucimar Rosa. Diversidade Étnico-Racial e Educação Infantil. Três Escolas, Uma Questão, Muitas Respostas. 1997. Dissertação (Mestrado em Educação). Universidade Federal do Mato Grosso do Sul, Campo Grande.

FISCHER, Rosa. Televisão e educação: fruir e pensar a TV. Belo Horizonte: Autêntica, 2001.

\section{LEHER, Roberto, VITTORIA, Paolo}

e MOTTA, Vânia. Educação e Mercantilização em meio à tormenta Político-Econômica do Brasil

Germinal: Marxismo e Educação em Debate, Salvador, v. 9, n. 1, p.14-24, abr. 2017. ISSN: 2175-5604 14-24 Disponível em https://portalseer.ufba.br/index.php/revi stagerminal/article/view/21792/14337 Acesso em Nov. 2018
GATTI, Bernadete Angelina. Políticas docentes no Brasil: um estado da arte / Bernadete Angelina Gatti, Elba Siqueira de Sá Barreto e Marli Eliza Dalmazo de Afonso André. - Brasília: UNESCO, 2011.

HALL, Stuart. A centralidade da cultura. Educação \& Realidade, Porto Alegre, n. 22, v. 2, jul.-dez. 1997.

Heidrich, Regina de Oliveira. Análise de processo de inclusão escolar de alunos com paralisia cerebral utilizando as tecnologias de informação e comunicação [Tese de Informática na Educação]. Porto Alegre, RS, 2004. 230 Tese (Doutorado em Informática na Educação) - Universidade Federal do Rio Grande do Sul, 2004

KEATES, Simeon; CLARKSON, P. John. Countering design exclusion through inclusive design. $A C M$ SIGCAPH Computers and the Physically Handicapped, v. 44, n. 0, p. 69, 2002.

MARTINS, J. de S. A sociedade vista do abismo: novos estudos sobre exclusão, pobreza e classes sociais. Petrópolis, RJ: Vozes, 2002. 
Exclusão social e a

nova desigualdade. São Paulo: Paulus, 2009

\section{MARTINS (b) H.H.T.S. Metodologia}

Qualitativa de pesquisa. Educação e pesquisa. São Paulo, v.30, n.2 p: 289300, maio/ago. 2004.

MINAYO, Maria Cecília de Souza. Ciência, técnica e arte: o desafio da pesquisa social. In: (Org.) Pesquisa Social: teoria, método e criatividade. Rio de Janeiro: Vozes, 1994. p. 9-29

MOREIRA, A. F. B.; CANDAU, V. M. Educação escolar e cultura(s): construindo caminhos. In: Revista Brasileira de Educação. Rio de Janeiro, n. 23, maio/jun/jul/ago, 2003.

ORELOVE, F. P.; SOBSEY, D. R. N. Educating Children with Multiple Disabilities: a Transdisciplinary Approach. $3^{\text {a }}$ edição. Baltimore: Paul Brookes Publishing Co., 2000.

ROSEMBERG, Fúlvia. Literatura Infantil e Ideologia. São Paulo: Global, 1985.
SCOTT, Joan. Gênero: uma categoria útil de análise histórica. Educação $e$ Realidade, v. 20, n. 2, 1995.

SARAMAGO, A. R., GONÇALVES, A., NUNES, C., DUARTE, F. e AMARAL, I. Avaliação e Intervenção em Multideficiência. Centro de Recursos para a Multideficiência. Ministério da Educação. Direção-Geral de Inovação e de Desenvolvimento Curricular. Direção de Serviços de Educação Especial e do Apoio Sócio Educativo. Lisboa, 2004.

SILVA, T. T. Documentos de identidade: uma introdução ás teorias do currículo. Belo Horizonte: Autêntica, 1999.

SOLER, M. A. Didáctica multissensorial de las ciencias: un nuevo método para alumnos ciegos, deficientes visuales, y también sin problemas de visión. Barcelona: Ediciones Paidós Ibérica. 1999.

STROBEL, K. As imagens do outro sobre a cultura surda. Florianópolis: Editora UFSC, 2008. 
Periódico do Núcleo de Estudos e Pesquisas sobre Gênero e Direito Centro de Ciências Jurídicas - Universidade Federal da Paraíba V. 7 - Nº 03 - Ano 2018 - Educação, Gênero \& Direitos Humanos ISSN | 2179-7137 | http://periodicos.ufpb.br/ojs2/index.php/ged/index

UNESCO, Declaração de Salamanca sobre princípios, políticas e práticas na área das necessidades educativas especiais. 1994. 